\title{
The Development of Location Decision Making Support System for Chinese Shopping Malls from the Developers' Perspective
}

\author{
Youngsik Kwak ${ }^{1}$, Yoonjung Nam² ${ }^{2}$ Yoonsik Kwak ${ }^{3}$ and Yongsik Nam ${ }^{4}$ \\ ${ }^{1}$ Gyeongnam National University of Science and Technology, yskwak@gntech.ac.kr \\ ${ }^{2}$ Ph.D. Candidate, Hanyang University, jean@hanyang.ac.kr \\ ${ }^{3}$ Korea National University of Transportation, yskwak@ut.ac.kr \\ ${ }^{4}$ OpenTide China, namys118@opentide.com.cn
}

\begin{abstract}
This study aims to explore the factors that determine the attractiveness of shopping mall locations for developers, from the perspective of those who want to select site to open shopping malls in China, and to evaluate the relative importance of these factors. Through a literature review, shopping mall location, store attractiveness in the shopping mall, fit between target market customers and prices, and shopping mall image were identified as the four components in shopping mall attractiveness. The measurement variables under these constructs were also identified: size of the population within the catchment area, proximity, anchor store, tenant mix, number of stores, the shopping mall size, products, properties, and visual presentation. The preference among the four competing shopping malls in Beijing was measured after identifying the relative importance between the criteria for the four constructs and nine measurement variables through pairwise comparison using the AHP of the five experts. The researchers applied this model to four shopping malls in Beijing. Through the AHP analysis, the researchers found that the relative importance of the variables was in the following descending order: store attractiveness > fit between target market customers and prices > shopping mall image > location. Using the results, the researchers can establish $a$ Location Decision Making Support System for shopping mall in China.
\end{abstract}

Keywords: Shopping Mall, Location Decision Making Model, China, Anchor store, Tenants Mix

\section{Introduction}

A shopping mall is a large-scale commercial distribution facility equipped with departmental stores, fashion stores, and other general stores [1]. With the recent economic growth, shopping malls have been actively developed and operated in China. They are coming up in the existing commercial districts of large cities and upcoming commercial districts of developing cities. For example, China's largest shopping mall company, Wanda Group, has built 49 shopping malls_called Wanda Squares - throughout China. In addition, Singaporean Raffles Square has also been building a nationwide chain of malls, particularly in large cities [2]. Further, offline shopping malls are most actively being constructed in China, besides the Middle East and India. On the other hand, in the United States, a downward trend in the number of shopping malls has been reported [3].

A shopping mall is very important to the tenants, developers, and visiting customers. The attractiveness of the shopping mall is one of the biggest concerns to these three stakeholders. Differentiation from existing competitors and an attractive location are essential to the developers that select the location of a shopping mall and make large-scale capital 
investments in it, as the fulfillment of these requirements ensures that tenants open their stores in the mall. Further, only when a shopping mall is attractive, customers want to spend time and shop there. These three stakeholders use different criteria for evaluating the attractiveness of a shopping mall. As a result, the studies on existing shopping malls are divided into exploratory studies on the determinants of the attractiveness of shopping mall locations for developers and studies on the determinants of the attractiveness of shopping malls for visiting customers.

Despite the rapid development of offline shopping malls in China, the number of academic studies on them is relatively rare. On the other hand, similar to Korea, recently many studies in China are being conducted on the online shopping mall market in the country. Several studies on offline shopping malls have been conducted in Europe and India, but it is difficult to find such studies in the context of China [4]. Furthermore, very few studies on shopping malls have been conducted from the perspective of developers, although there are many studies on large-scale distribution commercial facilities from the customers' perspective.

This study aims to explore the factors that determine the attractiveness of shopping mall locations for developers, from the perspective of those who want to select site among several site alternatives for shopping malls in China, to evaluate the relative importance of these factors, to establish a Location Decision Making Support System for shopping mall in China. In practice, future shopping mall developers will be able to identify locations and development factors that ensure a competitive advantage for them in competing with existing shopping malls.

\section{Literature Review}

\subsection{Location as a Determinant of Shopping Mall Attractiveness}

The fact that location is the basic feature of attractiveness considered in location selection has a long academic history [3-6]. Location is important to both the developers, who decide the mall location, and the tenants, who decide whether to lease space in a shopping mall based on how many people are likely to visit it. It is also important to the customers, who evaluate whether it is a convenient location to visit.

The previous studies regarding location can be divided into twofold: "catchment area” and "time/distance proximity." Catchment refers to a geographical region where the operation of physical facilities involves people, things, and information [1]. Therefore, the catchment area and extent of attractiveness vary depending on the location of the shopping mall. The concept of catchment area is important to the developers and tenants; it is not particularly important to customers.

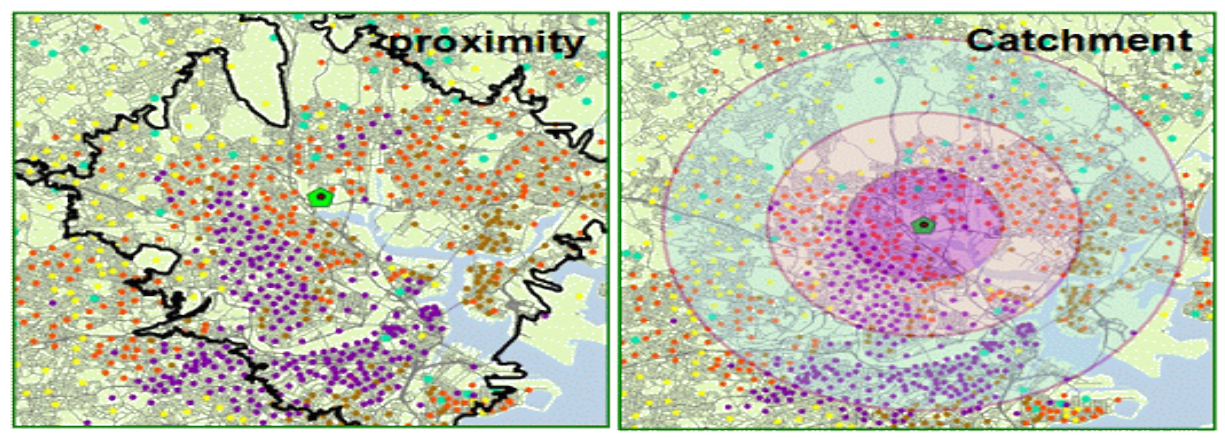

Figure 1. Imagery Example of Proximity and Catchment 
It is common to divide catchment areas into $1 \mathrm{~km}, 2 \mathrm{~km}$, and $3 \mathrm{~km}$ areas in practice. The inside of the catchment area, located within $1 \mathrm{~km}$, is called the primary trade area; the area located within $2 \mathrm{~km}$ is the secondary trade area; and the area located within $3 \mathrm{~km}$ the tertiary trade area [8]. The size of the population in these three catchment areas or the number of customers in this target market is extremely important to the developers and tenants. Since Huff(1964), it has been a consistent argument that the attractiveness of a shopping mall declines as the catchment area moves farther out; this has been established as the concept of catchment area. Developers need to examine the location where there are a large number of customers within the catchment area.

However, catchment area does not include physical barriers such as rivers, mountains, or main roads. The time to access the shopping mall may vary for customers due to such physical obstacles and a difference in accessibility, even if they are at the same distance from the mall. Therefore, the concept of "proximity" includes the aspect of time in addition to distance. In practice, the destination is sometimes measured as within reach in twenty minutes at the most congested time. Developers and customers objectively view the time/distance proximity within the catchment area [8].

\subsection{Store Attractiveness as a Determinant of Shopping Mall Attractiveness}

One of the success factors for developers and tenants is the arrangement or assortment of stores in the shopping mall. The variables related to store attractiveness can be largely divided into four types based on previous studies.

First, it has been explored that anchor stores in the shopping mall that attract attention determine the success or failure of the shopping mall. An anchor store is a store with a reputable brand that can attract customers from around the shopping mall [9]. This representative store determines the visits to the shopping mall, number of visiting customers, retail price levels of the shopping mall, and profit level. Yuo et al., (2004)'s empirical study reported that the representative store has relevance to the expenses for entering the shopping mall [10]. Therefore, the shopping mall's attractiveness may vary depending on the presence of the representative store and the extent to which it can attract customers.

The second variable, tenant mix, refers to the type and number of product categories in the shopping mall that are provided to customers or to the composition ratios of the types of other stores [11]. Empirical studies show that the appropriate mix of product categories increases the revenue of the shopping mall, and in the reverse case, decreases the revenue [3] [10]. Consulting companies such as PwC also consider the tenant mix as a variable when measuring the attractiveness of shopping malls [12].

The variables related to the tenants mix include the number of tenants and shopping mall size. Yuo et al., (2004) and Wesley(2006) empirically suggest a relationship between the size of the store, number of tenants, and sales performance. According to them, the customer base and sales performance are better if the tenant mix is more diverse, the number of tenants is larger, and the shopping mall is bigger [13]. Lekshmi and Jawaharrani (2012) found that the variable that had the most influence on the selection of shopping mall was the diversity of tenants. PwC also points out that the size of the shopping mall determines customer attraction [3].

\subsection{Customer-Price Fit as a Determinant of Shopping Mall Attractiveness}

Price is a variable that has not been addressed adequately in previous research on shopping mall selection from the developer's perspective [4]. However, in case of developing countries such as India and China, price may be a variable of attractiveness in countries or cities with a 
large gap between the rich and the poor. Furthermore, from the customers' perspectives, price has been regarded as a determinant for selection shopping mall. Sinha and Banerjee (2004) argue that in large-scale commercial distribution facilities, price policy and promotion policy are closely related to one another [14]. Wesley et al., (2006) argue that the variable determining the satisfaction or dissatisfaction of customers in the shopping mall is the price of the goods they encounter [13].

The potential customers in each catchment area are determined by the location of the shopping mall, and it can be assumed that the price elasticity of these potential customers varies depending on the location of that shopping mall. Therefore, this study applies the degree of the fit between the customers within the catchment area and the shopping mall prices to the model for shopping malls from the developers' perspective.

\subsection{Mall Image as a Determinant of Shopping Mall Attractiveness}

Customers' behavior in selecting a shopping mall is the result of past individual customer experience. In other words, one of the variables that determine the number of customers who enter shopping malls is past experience at that shopping mall. The concepts that have previously been dealt with in research studies with regard to experience related to shopping malls are ambience, image, and experience module.

Lekshmi and Jawaharrani (2012) consider ambience as an influencing variable in shoppers' selection of a mall; however, they do not identify how ambience is defined specifically or what its components are [3]. However, in explaining ambience, Taneja (2007) refers to the products and services found in the shopping mall and the stores and their presentation [4].

The previous studies asserted that these several variables together determine the image of a shopping mall, which then influences customers' selection of the shopping mall. Levy and Weitz (2013) have defined shopping mall image as the sum of functional and emotional attributes [1]. It appears that ambience and image are not clearly distinguished in the literature. Hunter (2006) and Ooi and Sim (2007) stated that shopping mall image is determined by the anchor store and the physical nature of the shopping mall [15-16]. Therefore, the elements that create the ambience and the elements that create the image are similar. These common characteristics can be referred to as an experience module.

Schmitt and Simonson (2009) summarized the experience module that is experienced from a product or service. They defined the 4Ps (product, presentation, publication, properties) that determine image or style as an experience module [17]. The determinants of shopping mall image or ambience discussed so far can be classified using the experience module of 4Ps. Therefore, it is judged that the satisfaction and dissatisfaction, which are the result variables for the experience that have been measured with the performance variables of the shopping mall by Wesley et al. (2006), can be measured using the experience module 4Ps [13].

\section{Research}

\subsection{Measurement Variables for Shopping Mall Attractiveness Decision Models}

The measurement variables for shopping mall location decision models from a developer's perspective discussed in the literature review may be summarized as shown in Figure 1. 


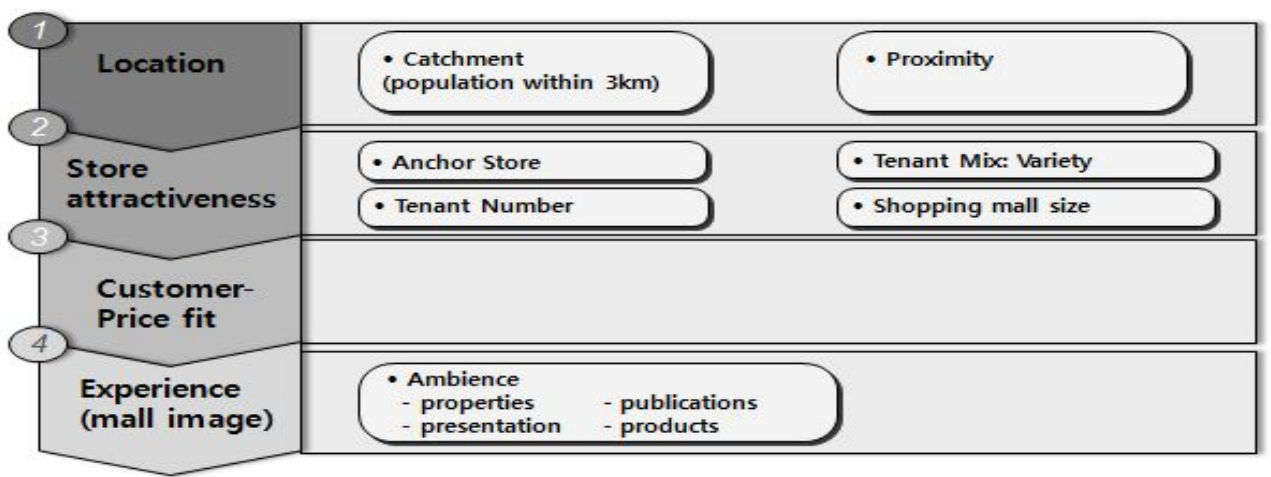

Figure 1. The Measurement Variables of Shopping Mall Attractiveness Decision Models

The major components of the location decision system are location, store, customer price fit, and mall image. Sub-measurement variables were also determined under each major component. Location was classified into tertiary trade area and proximity. Four different measurement variables such as anchor store, tenant mix, number of stores, and size of shopping mall were used for store attractiveness. Shopping mall image was determined by the experience module of $4 \mathrm{Ps}$.

\subsection{Research Objectives in Beijing}

In this study, the shopping malls in Sanlitun, Solana, Huatang and Indigo, which are all major commercial districts located in the central and northeastern parts of Beijing, were estimated to relative importance of four criteria for the location decision system. Since they are located on the same or major roads, these four commercial districts can be seen as competing commercial trade area accessible by the same customers. Because China has unique price response to price change, product features, brand equity, and pricing schemata, the researchers limit the study object to Beijing area [18-20].

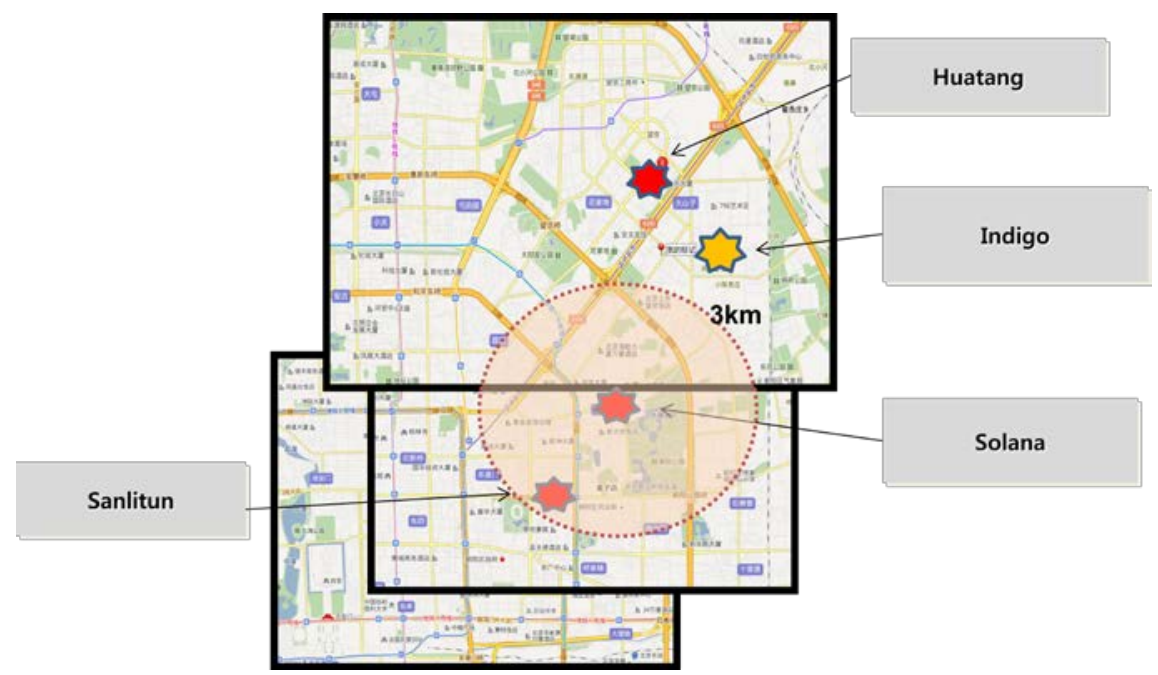

Figure 2. Locations of the Commercial Districts in Beijing Investigated in this Study 


\subsection{Research Method}

As the components of the shopping mall location decision models are hierarchically classified by the criteria of the major construct and sub-measurement variables and the four commercial districts to be studied need to be comparatively measured for each criterion, the analytic hierarchy process (AHP) was used to measure their relative importance. For the AHP, a pairwise comparison was carried out between each criterion for the measurement variables at the first stage and for the major construct at the second stage. Finally, a pairwise comparison was carried out for the four shopping malls on each criterion for the measurement variables.

The quantitative variables in the criteria for the measurement variable were measured using primary and secondary data. The catchment area was measured as shown in Figure 4 in the tertiary catchment area with geometric information found on internet. Of the variables related to stores, representative store, number of stores, and tenant mix were measured through observation by the researcher who visited shopping malls in each commercial district, and the information on the size of these shopping malls was obtained from their website. This way the absolute comparison of the four shopping malls using quantitative variables was completed. On the other hand, the relative importance of these variables was determined subjectively by the respondents.

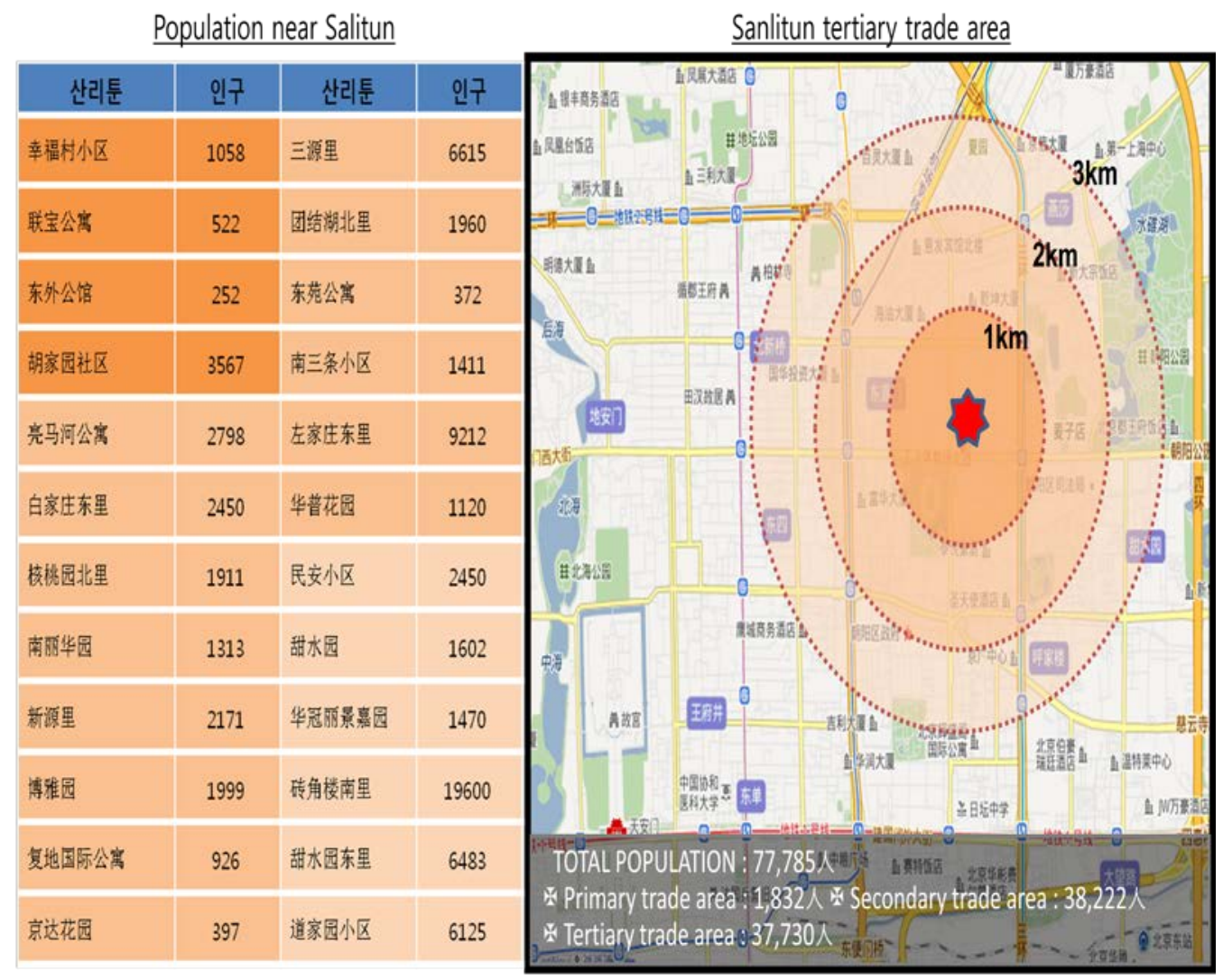

Figure 3. AHP Structure of the Study 


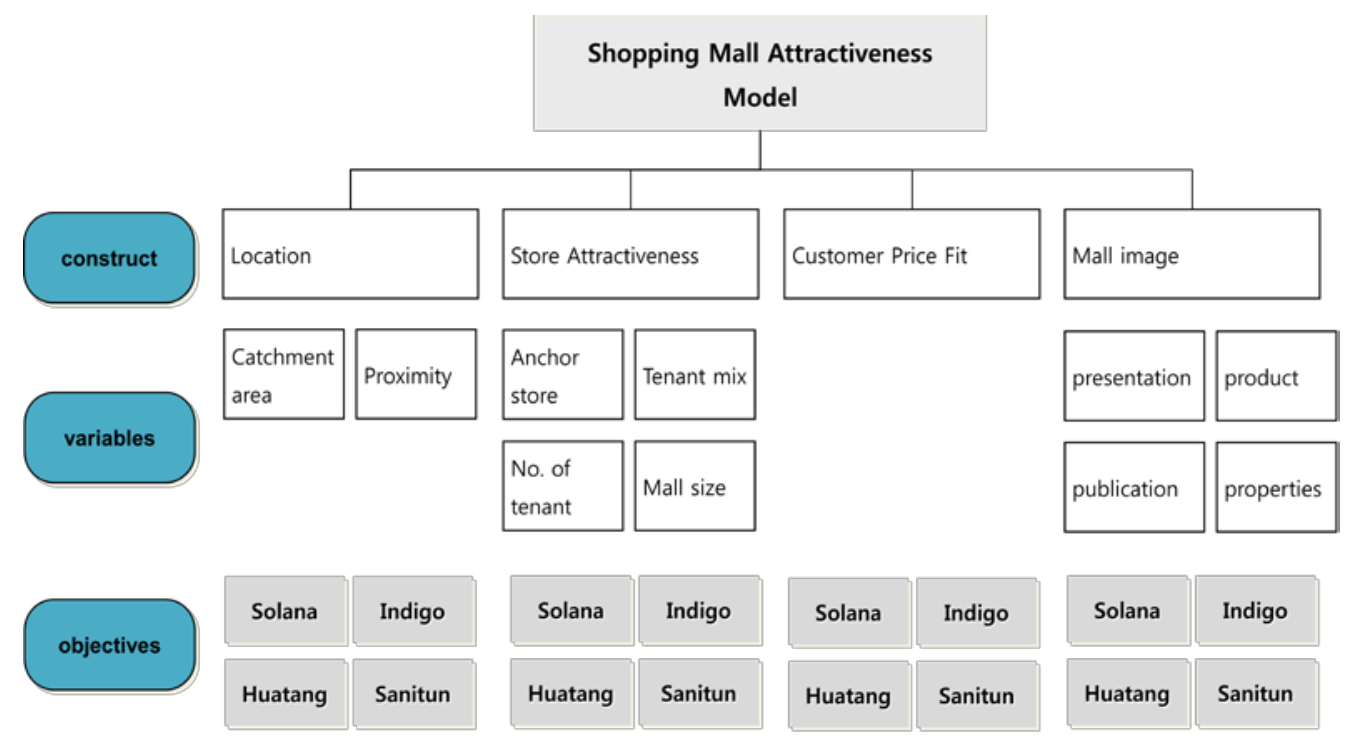

Figure 4. Example of Measuring the Size of the Population in the Catchment Area

The qualitative variables were subjectively assessed using the Delphi method in the pairwise comparison by three professionals from the consulting industry and two professors majoring in marketing. Respondents 1 and 2 were Koreans, and respondent 3 was a Chinese working with a consulting firm in Beijing and helping Korean companies enter the Chinese market. All three professionals had over five years of experience in consulting. The two professors majoring in marketing were both Koreans and professors at four-year universities in Korea. Both of them had over ten years of experience in distribution network-related projects in China. The Delphi method was conducted to generate the responses of the five experts with two rounds. The results of the first round were shown to the respondents, who were then asked to provide comments to help modify the process.

Following a literature review, out of the variables used as criteria for the measurement in the AHP, publication was removed from the actual measurement, since the respondents' comments indicated that it did not affect the evaluation of the attractiveness of Chinese shopping malls. EXPERTCHOICE program was used to conduct the AHP and calculate the relative importance and preference among four trade areas.

\section{Results and Discussion}

\subsection{Relative Importance among Measurement Variables and Constructs}

The five experts' pairwise comparison responses to the criteria for selecting shopping malls from the developers' perspective discussed in the literature review were examined with consistency index. If the consistency index is less than 0.1 , the researchers confirm to include the response to results. All of the response showed a consistency index of less than 0.1. Therefore, the average of these five experts is reported as the result value of the attractiveness decision models from the developers' perspective investigated in this study(Figure 5). 
First, according to the analysis results for the major components in the shopping mall attractiveness decision models determined by the experts through the AHP analysis, the relative importance of the variables was in the following descending order: store attractiveness $(0.339)>$ fit between target market customers and prices $(0.287)>$ shopping mall image (0.212) > location (0.161). The respondents evaluated shopping mall stores to be the most important criteria for selecting shopping malls; on the other hand, location proved to be the least important.

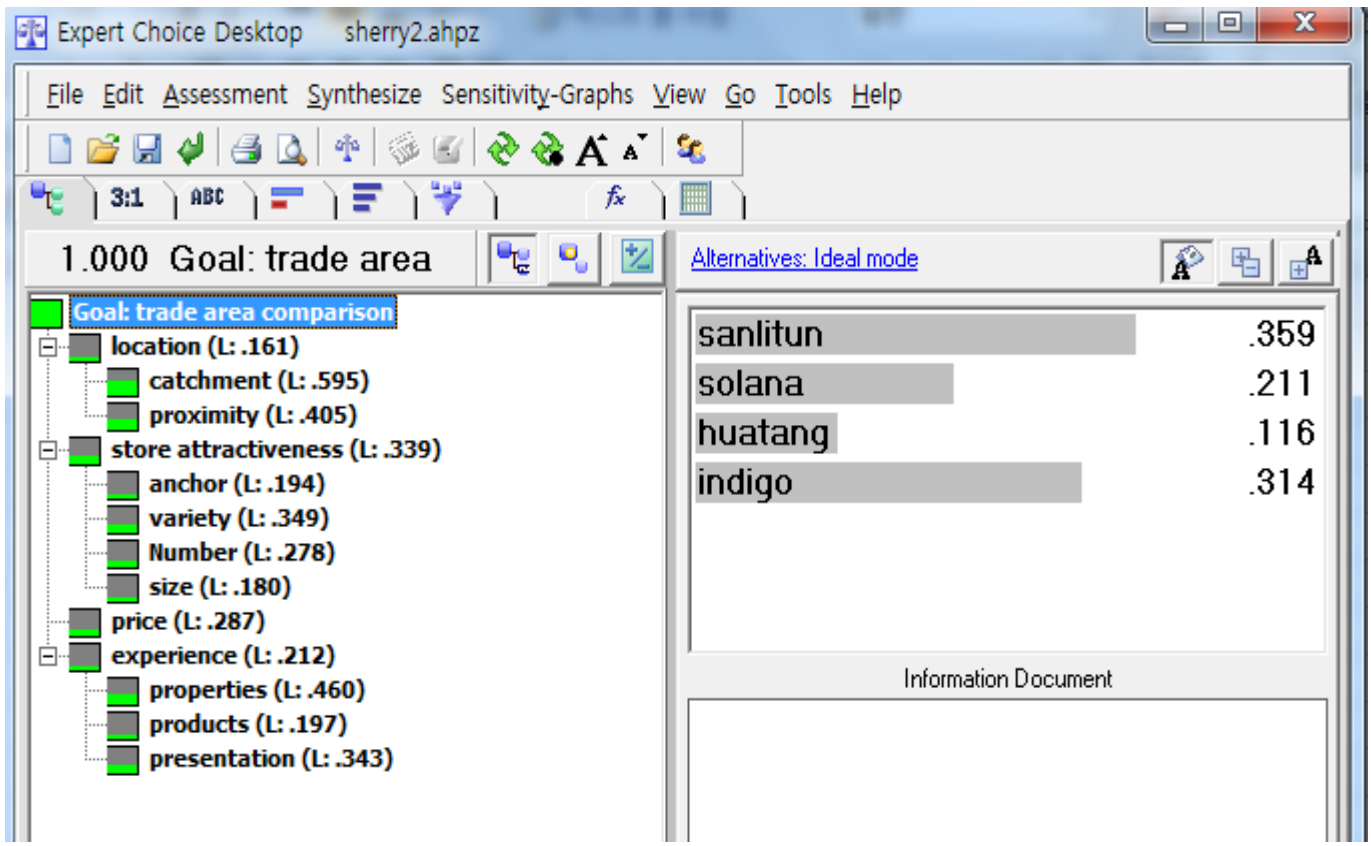

Figure 5. Result of the AHP

The analysis of the measurement that constitute the aspect of "store attractiveness"- the criteria for the major construct of the highest relative importance-revealed that their relative importance was in the following descending order: tenant mix $(0.349)>$ number of stores $(0.278)>$ anchor store $(0.194)>$ shopping mall size $(0.180)$. In other words, the experts believed that the tenant mix of product categories that are provided in the shopping mall must be good in order to attract customers.

The analysis of the criteria for the measurement of the 3Ps out of 4Ps that constitute the aspect of shopping mall image revealed that their relative importance was in the following descending order: shopping mall properties $(0.460)>$ visual presentation $(0.343)>$ products (0.197). The experts appeared to emphasize the most on the aspect of shopping mall properties in developing the shopping mall.

In terms of location, the catchment area within $3 \mathrm{~km}(0.595)$ appeared to be more important than the time/distance proximity of the shopping mall (0.405). Therefore, developers need to consider the size of the population within the catchment area as the most important aspect when selecting the location for the shopping mall.

\subsection{Calculation of Shopping Mall Preference}

The experts provided the performance value by criterion for the four shopping malls based on the relative importance of the shopping mall attractiveness model components derived as shown on the left side of Figure 5. By examining the experts' subjective judgment and the 
actual value of the quantitative variables, Sanlitun (0.359), where the traditional commercial district has been redeveloped and which is the closest to downtown Beijing, was found to be the most preferred commercial district. This was followed by Indigo Shopping Mall, which has been newly developed using Singapore-based capital in 2012 and is directly connected to the main roads along Wangjing district, the airport, and Shunyi and Miyun areas. Solana Shopping Mall, which was developed in the mid-2000s, was the next preferred shopping mall, while the preference for Huatang, which is a lifestyle shopping mall close to the Wangjing area in Beijing, was ranked the lowest.

\section{Conclusion}

This study aims to establish location attractiveness models for shopping mall to help developers make decisions. To develop these models, this study explores the four components and nine measurement variables through the literature review from the developers' perspective, and evaluates the relative importance among these factors.

Following a literature review, shopping mall location, store attractiveness in the shopping mall, fit between target market customers and prices, and shopping mall image were identified as the important components in shopping mall development. The following subvariables under these constructs were also identified: size of the population within the catchment area, proximity, anchor store, tenant mix, number of stores, size of the shopping mall, products, properties, and visual presentation. The preference among the four competing shopping malls in Beijing was measured after identifying the relative importance between the criteria for the measurement variables and four major construct through pairwise comparison using the AHP responses of the five experts.

As a result, store attractiveness in the shopping mall appeared to have the highest relative importance. The experts appeared to have determined that the key to success is the attractiveness of the stores that the developers collaborate with after building the mall.

Additionally, the fit between the customers within the catchment area and the prices was ranked the second highest in relative importance out of the criteria for the major construct. Considering that the Chinese had a GDP per person of over \$5,000 in 2012, the experts determined that the presence of the consumption available for purchase in the shopping mall was important to the developers. In the Beijing market, a gap between the rich and the poor and the geographic distribution of a population with different income levels exist. This shows that there is a need to consider the level of income of the population in the catchment area when developers select a location.

According to the results of the criteria for the measurement, whether or not tenant mix and number of stores are the most important among the components of store attractiveness in the shopping mall needs to be verified from the tenants' perspective. Whether customers prefer a larger or a smaller number of categories must also be rechecked.

This study identifies the decision-making factors for shopping mall development that should be considered by the developers of Chinese offline shopping malls. In practice, this study provides future shopping mall developers with insights into location selection and development that could help them gain a competitive advantage when competing with existing shopping malls.

The experts who participated in this study point out that the results of this study are applicable only in Beijing. According to them, the shopping mall attractiveness model components and their relative importance may be different between Beijing and Shanghai, as Beijing is a highly accessible and flat area where the traditional commercial districts and newly developed commercial districts compete with each other, whereas Shanghai has many 
commercial districts artificially developed due to urban expansion and road construction and few traditional commercial districts. In addition, this study had limitations in that the developers with large capital did not participate in this study as evaluators.

\section{Acknowledgements}

This work was supported by Gyeongnam National University of Science and Technology Grant in 2013.

\section{References}

[1] M. Levy and B. A. Weitz, "Retail Management”, McGraw Hill, (2013).

[2] Fashion Channel, Development of Chinese shopping malls and Prospects for Korean Brands, (2012) April, pp. 178-181.

[3] R. S. Lekshmi and Jawaharrani, "Shopper Behavior in Malls", Asian Academic Research Journal of Multidisciplinary, vol. 1, (2012), pp. 52-63.

[4] K. Taneja, "Mall Mania in India: Changing Consumer Shopping Habits", Unpublished dissertation, University of Nottingham, (2007).

[5] D. L. Huff, "Defining and estimating a trade area”, Journal of Marketing, vol. 28, (1964), pp. 29-37.

[6] A. Ghosh and S. C. Craig, "Formulating retail strategy in a changing environment", Journal of Retailing, Spring, (1983), pp. 56-66.

[7] M. Kirkup and M. Rafiq, "Managing Tenant Mix in New Shopping Centres”, International Journal of Retail \&Distribution Management, vol. 22, (1994), pp. 29 - 37.

[8] S. Tanwar, N. Kaushik and V. K. Kaushik, "Retail Malls: New Mantra for Success", Sri Krishna International Research \& Educational Consortium, vol. 2, (2011), pp. 103-113.

[9] H. Konishi and M. T. Sandfort, “Anchor stores”, Journal of Urban Economies, vol. 53, (2003), pp. 413-435.

[10] T. Yuo, N. Crosby, C. M. Lizieri and P. McCann, “Tenant mix variety in regional shopping centres: Some UK empirical analyses”, Working Paper, University of Reading, Reading, vol. 29, (2004).

[11] Y. Kim, L. Jolly, A. Fairhurst and K. Atkins, "Mixed-Use Development: Creating a Model of Key Success Factors”, Journal of Shopping Center Research Consumer, Spring/Summer, vol. 12, (2005), pp.53-75.

[12] www.pwc.com.

[13] S. Wesley, M. LeHew and A. G. Woodside, "Consumer Decision Making Styles and Mall Shopping Behavior: Building Theory Using Exploratory Data Analysis and The Comparative Method”, Journal of Business Research, vol. 59, (2006), pp. 535-548.

[14] P. K. Sinha and A. Banerjee, "Store Choice Behavior in an Evolving Market”, International Journal of Retail and Distribution Management, vol. 32, (2004), pp. 482-494.

[15] G. L. Hunter, "The Role of Anticipated Emotion, Desire and Intention in the Relationship between Image and Shopping Centre Visits”, International Journal of Retail and Distribution Management, vol. 34, (2006), pp. 709-721.

[16] J. T. L. Ooi and L. L. Sim, “The Magnetism of Suburban Shopping Centers: Do Size and Cineplex Matter?”, Journal of Property Investment and Finance, vol. 25, (2007), pp. 111-135.

[17] B. Schmitt and A. Simonson, "Marketing Aesthetics", The Free Press, (2009).

[18] Y. Lee, W. Youn, J. Lim, Y. Nam and Y. Kwak, “OpenTide China’s Pricing Decision-making Support System 2.0 for Digital industry in China”, International Journal of u- and e- Service Science and Technology, vol. 3, (2010), pp. 11-20.

[19] Y. Kwak, Y. Lee and Y. Kwak, "The Development of Software Pricing Schemata and its Application to Software Industry in Korea”, International Journal of u- and e- Service Science and Technology, vol. 3, (2010), pp. 43-50.

[20] Y. Nam and Y. Kwak, "The development of dynamic brand equity chase model and its application to digital industry based on scanner data”, International Journal of u- and e- Service Science and Technology, vol. 2, (2009), pp. 29-36. 


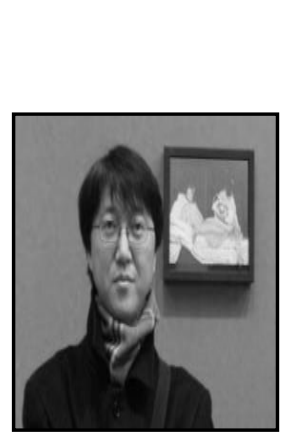

\section{Authors}

Youngsik Kwak received a B.B.A. degree from Sungkyunkwan University, Seoul, Korea, in 1990, a MBA. degree from Sungkyunkwan University, Seoul, Korea, in 1994, a M.S. degree from Texas Tech University, Lubbock, TX, in 1997, and a Ph. D. degree from Sungkyunkwan University, Seoul, Korea in 1999, in marketing. He had been a marketing consultant for Daewoo Economic Research Institutes from 1999 to 2002. Currently he is an associate professor in the Department of Venture and Business, Gyeongnam National University of Science and Technology, Jinju, Korea. His research interests include pricing on- and off-line.

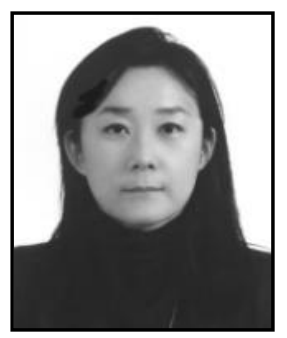

Yoonjung Nam received a B.B.A. degree from Sangmyung University, Korea in 1996, an MBA. Degree from Sungkyunkwan University, Korea in 1999, and now is a Ph.D. candidate in Hanyang University, Korea in tourism. She has been a marketer for 2 years in IT industry and 11 years for hospitality industry from 1999 to present. Her research interests include all aspects of hospitality and leisure marketing.

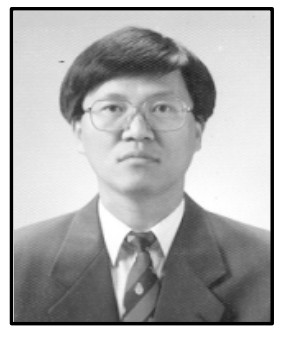

Yoonsik Kwak received his B.S. degree in Electrical Engineering from the University of Cheongju in 1984, his M.S.E.E. degree from the University of Kyunghee in 1986 and his Ph.D. degree from the University of Kyunghee in 1994. He worked at Korea National University of Transportation in the Department of Computer Engineering and rose to the level of Full Professor. His research interests are in the areas of signal processing, Internet communication, microcomputer system, and applications of these methods to mobile system.

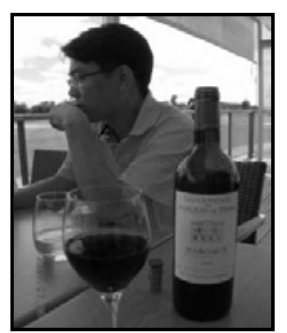

Yongsik Nam received a B.B.A. degree from Sungkyunkwan University, Seoul, Korea, a MBA. degree from Sungkyunkwan University, Seoul, Korea, in 1995, and a Ph. D. degree from Sungkyunkwan University, Seoul, Korea in 1999, in marketing. He had been a China marketing consultant for Samsung OpenTide China from 2001. Currently he is CEO in Samsung OpenTide China. His research interests include on- and off-line digital marketing. 
International Journal of Smart Home Vol.7, No.5 (2013) 